\title{
Innovation's Role in Nowadays Society and the Ways to Generate Competitive Intelligence and Accountability: Case of Romania
}

\author{
Veronica Adriana Popescu ${ }^{1}$, Gheorghe N. Popescu ${ }^{1}$ and Cristina Raluca Popescu ${ }^{2}$ \\ ${ }^{1}$ Academy of Economic Studies, Bucharest (ROMANIA) \\ ${ }^{2}$ University of Bucharest, Bucharest (ROMANIA)
}

\begin{abstract}
Nowadays society is governed, on a constant basis, with ambiguous and uncertain economic trends and insecurity. Our research paper takes into account the solutions proposed by innovation in a society in which the dream of competitive intelligence and accountability seem sometimes to fail.
\end{abstract}

The key issue that our ideas are based on for us, as research economists, is that the future of any type of society, including the Romanian one, is related to the complex process of innovation and in the capacity to better anticipate the need of correct and reliable knowledge. Furthermore, we strongly believe that providing better and improved knowledge at the right time and in the right place is a form of art that each of us should learn to handle better and better. But knowledge should also be turned into useful value, part which is done through the process called knowledge management. Knowledge management is, according to us, the only reliable source that can truly ensure the competitive advantage of any nation. A key element in the competitive advantage and also in the competitive intelligence process is the existence of well functional and well developed learning organizations.

Our research paper starts with an introduction in which we have emphasized the place of innovation in learning organizations and which are the main aspects that generate innovation; continues with a literature review in which we have presented the opinions that academics, researchers and specialists regarding the use of innovation through competitive intelligence and accountability; presents in a theoretical approach what knowledge, knowledge management, innovation, competitive advantage, competitive intelligence, learning organizations are and also in what manner they can influence the evolution of the society; focuses on a case study of the Romanian's society, in nowadays turbulent moments generated by the global economic crisis.

Keywords: knowledge management, global economic crisis, competitive advantage, competitive intelligence, learning organizations.

\section{Introduction}

The scope of our research paper is to present the subject of innovation in relation to knowledge, knowledge management, competitive advantage, competitive intelligence and learning organizations, corroborated with the challenges that all these are facing in the year 2012. Due to our belief that innovation does not exist unless it is triggered by knowledge, which can be best valued by knowledge management, and furthermore generate competitive advantage, we also deal in our paper with the subject of learning organizations.

Our interest in this particular field started for us, as research economists, in order to

Copyright (C) 2012 Veronica Adriana Popescu, Gheorghe N. Popescu and Cristina Raluca Popescu. This is an open access article distributed under the Creative Commons Attribution License unported 3.0, which permits unrestricted use, distribution, and reproduction in any medium, provided that original work is properly cited. Contact author: Veronica Adriana Popescu E-mail: popescu_va@yahoo.com 
find out the state that it exists worldwide and after that to be able to define its role and its development potential in Romania.

Of course, knowledge in terms of the fully use of information and data, has always existed and has always motivated people to go further and further, but knowledge management is far more than knowledge and also far more than knowledge combined with people's skills, competences, ideas or intuition. For us, knowledge management is the ageless and broad process that governs the creation, dissemination and utilization of knowledge, which is much more than knowledge analysis, knowledge planning or knowledge technology. Moreover, knowledge management represents for us the process of audit of intellectual assets, which has unique potential and seeks new opportunities, products and services in order to gain and sustain competitive positions. Furthermore, the notions of knowledge and knowledge management can be associated as well with the complex notion of learning organizations. In this matter, learning organizations are those companies in which access to new and improved knowledge is constantly facilitated, and that helps all the members to embrace it in order to generate change and better perspectives in terms of competitiveness.

The most important part of our research paper focuses on the place and the role of knowledge management in Romania. In our opinion, Romania is a country where one can find great potential in terms of knowledge, but unfortunately its use is not at its real capacity. The idea that our case study starts with is that knowledge represents both the starting point and the driver for any economy, and therefor knowledge is the result of learning which provides the only form of sustainable competitive advantage. The question that comes next into discussion is the problem that refers to the use of knowledge in Romania. In order to create a clear image on knowledge and knowledge management in Romania, another great concern for us turned out to be the subject of learning organizations.
Our attempt to find out more information regarding learning organizations' perspectives in Romania was done due to our strong believe that, in the next future, the competitive advantage of any country will stand into its capacity to generate, evaluate and value knowledge, and moreover will depend on the competences and abilities of individuals and companies to create innovative economic strategies, capable to make a difference in a continuously ruthless environment. An awakening moment was the recent economic crisis and its dramatic effects on the countries worldwide, effects from which Romania could stand no change in escaping. As dramatic results of the economic crisis in Romania, we can hereby mention the salary cuts (in most cases with even more than $45 \%$ ), the rapid growth of unemployment, the increased inflation, the increasing imbalance in the population economic level, and so on.

In order to show concluding and pertinent results in our case study on Romania we have used, in terms of research methodology, questioners in which we have tried to find out the perception of individuals upon the importance of key points such as the correct use of knowledge, the role of knowledge management in an organization, the implementation of innovation, the acceptance of technology, and the role of being part of an active learning organization centered on gaining competitive advantage. Our research method focused on 200 subjects (adult individuals) from 5 organizations in Romania, and was done on a period length of three years, respectively between 2009 and 2011.

As an interesting phenomenon, in terms of individuals' perception on knowledge and knowledge management at learning organizations level, we have seen that, at a first glance, individuals show a great availability and a high openness rate in terms of embracing, for example, new innovative methods and new technologies, but, in reality, the organizations confront themselves with far more problems than the ones of implementing or not new technologies, of using correct or not 
knowledge and so on. Far more important, in terms of obstacles that learning organizations have to face, are the ones regarding the motivations of their employees. According to the results generated by our study and the use of our research methodology, an unsatisfied employee in any type of organization, in terms of money and bonuses motivation and/or the opportunity to promote at the organizational level and/or a conductive organizational environment, may be extremely reluctant to anything that relates to future learning processes or tasks or working openness in terms of knowledge innovation.

It is a clear fact that our paper mainly addresses to academics and researchers, but can also be regarded as a starting point for further research analysis for managers and practitioners in general.

\section{Literature Review}

The literature review of our research paper puts an emphasis on the importance of innovation and innovative skills that a society in continuous development should mainly focus upon. Moreover, this part concentrates on studies made by academics and researchers that refer to the complex relation that exists between innovation innovation skills - knowledge - knowledge management - learning organizations. In this matter, most of the literature that we have examined for our paper focuses on technological innovation.

Firstly, we are going to discuss the importance of innovation and what we mean when we refer to innovation and innovation skills in our study. Innovation represents the creation of better products, services, processes and technologies, which implicate a complex use of ideas, and that, have to be accepted by the society, markets and government. We believe there is a complex set of skills that individual and organizations might have in order to be able to generate innovation. Of course, the impact of innovation on demand for skills is very dependent on the type of innovation and the context. In this case, the theoretical and empirical literature has shown that innovation at the level of process generates, in most cases, job losses. However, the theoretical and empirical literature suggests that product innovation is positive to employment levels as it will often result in an increase in demand for certain products. While taking into account the subject of innovation in terms of organizations, innovation may be connected with positive changes in efficiency, productivity, quality, competitiveness, and so on. Also, it is generally known that all types of organizations can innovate (A

CRIC Report for the Department of Trade and Industry, September, 2005); the main conditions are desire to improve and availability of resources. In terms of literature review, on one hand, organizational product innovation is positive to employment and on the other hand, organizational process innovation is negative to employment. A problem that concerned us is the manner in which a country's environment can influence the type of product innovation developed by an organization. Whitley (2000) linked national level characteristics with product innovation and grouped the national systems of economic activities into six categories, respectively: state organized, highly coordinated, collaborative, compartmentalized, industry coordinated and fragmented. Due to this segmentation, institutional differences between market economies conducted to variations in innovation strategies and resulting product innovations vary in terms of technical and user novelty, differentiation in product and quality, familiarity with organizational competences and with current knowledge.

Secondly, we are going to present the place of knowledge and knowledge management as key drivers of today's society. In this matter, Webster's New Collegiate Dictionary (http://www.merriam-webster.com/) defines knowledge as "the fact or condition of knowing something with familiarity gained through experience or association." Moreover, knowledge represents the full utilization of information and data, coupled with the potential of people's skills, competencies, ideas, intuitions, commitments and motivations and can be 
associated with "assets" such as people, money, leverage, learning, flexibility, power and competitive advantage. Furthermore, compared to capital, labor or land, knowledge is more relevant to sustained business. A holistic view considers knowledge to be present in ideas, judgments, talents, root causes, relationships, perspectives and concepts. We are going to use the term knowledge in our study referring to the information stored in the individual brain or encoded in organizational processes, documents, products, services, facilities and systems, that consist the basis for, and the driver of, our all the economies. In our opinion knowledge is the result of learning which is capable to generate the only real and sustainable competitive advantage. While analyzing knowledge management we can state that it is an emerging field which can contribute a lot to the economic and management science. The term knowledge management started to be used at a worldwide level at the beginning of 1990s, but it is important to note here that the debate on this topic had started much earlier (Hayek, 1945; Bell, 1978). Speaking about knowledge management, we can note the following aspects: Drukes (1960) was the first to present the term knowledge worker; Senge (1990, 1994, 1999) showed that organization can learn from past experiences stored in corporate memory systems; Barton-Leonard (1995) documented the case of chappual steel as knowledge management success story; Nonaka and Takenchi (1995) studied how knowledge is produced, used, and diffused within organizations and how such knowledge contributed to the diffusion of innovation; and also a number of people recognized the growing importance of organizational knowledge as a competitive asset (Sveiby, 1996 and 1997; Nortan \& Keplan, 1996; and Edvineson \& Malone, 1997).

Thirdly, we are going to stress the role of learning organizations, threw the perspective of literature review studies. As we have discovered in our research process, a number of practitioners have suggested effective and innovative environmental programs faced in time with different types of barriers most of them at the organizational level (Kirkland and Thompson, 1999), (Allenby, 1999), (Klein and Sorra, 1996). The concept "learning organization" has its "founders" in the person of specialists Peter Senge, Chris Agyris, Donald Schon, and Margaret Wheatley. In terms of definitions, a learning organization is a term given to a company that facilitates learning to its members and developed a specific mechanism that allows it to continuously adapt to change. Learning organizations are forced by the environment in which they act and live to change accordingly, so they maintain their competitive advantage.

\section{Research Methodology}

The research methodology that we have used in our paper is as follows: for the first part of our paper we have used data gathered from existing research papers in terms of literature review, theoretical background, definitions and characteristics of notions such as innovation, innovation skills, knowledge, knowledge management and learning organizations; for the second part of our paper we have used our personal data gathered during the years 2009, 2010 and 2011, concerning adults individuals beliefs concerning the organization in which they work.

In order to show concluding and pertinent results in our case study on Romania we have used, in terms of research methodology, questioners in which we have tried to find out the perception of individuals upon the importance of key points such as the correct use of knowledge, the role of knowledge management in an organization, the implementation of innovation, the acceptance of technology, and the role of being part of an active learning organization centered on gaining competitive advantage. Our research method focused on 200 subjects (adult individuals) from 5 organizations in Romania, and was done on a period length of three years, respectively between 2009 and 2011. The data were processed using SPSS and EXCEL programs at the end of the year 2011. 


\section{Innovation Perspectives for a Society in Continuous Development}

The innovation perspective of each country lies in its desire to become more and more developed and gain a strong economy in time. Moreover, strong economies tend to invest far more than other economies in novelty and innovation skills and processes in their constant quest of having long term competitive advantages.

\section{Innovation and Innovation Skills, a Theoretical Approach}

The study that we made puts a particular emphasize on the role and importance of innovation, in a society mainly centered on combining the skills of individuals with their capacity to generate, sort, absorb and use innovation and also with their specific competences.

In our attempt to create a clear theoretical background regarding innovation and innovation skills, we start by defining and characterizing these terms.

Firstly, innovation represents the creation of better products, services, processes and technologies, which implicate a complex use of ideas, and that, have to be accepted by the society, markets and government. According to Freeman (1982), "industrial innovation includes the technical, design, manufacturing, management and commercial activities involved in the marketing of a new (or improved) product or the first commercial use of a new (or improved) process or equipment". Moreover, Drucker (1985) states that "innovation is the specific tool of entrepreneurs, the means by which they exploit change as an opportunity for a different business or service". Also, according to UK DTI (2004), "innovation is the successful exploitation of new ideas". Albury (2005) believes that "successful innovation is the creation and implementation of new processes, products, services and methods of delivery which result in significant improvements in outcomes, efficiency, effectiveness or quality" and Hartley (2006), states that innovation is "the successful development, implementation and use of new or structurally improved products, processes, services or organizational forms". In the same way, Jacobs and Snijders (2008) state that innovation is "something new being realized with (hopefully) added value".

Secondly, innovations skills refer to the attributes that an individual or an organization has in order to better value the innovation and to get the existing potential out of the innovation process. Innovation skills are usually a combination of cognitive, behavioral, functional and technical skills.

\section{Innovation and Innovation Skills, as Drivers of Nowadays Society}

We strongly believe that innovation together with innovation skills are one of the main drivers of nowadays society. In this context, specialists have shown that innovations vary along at least five dimensions, as follows: the type and degree of novelty of the innovation, the type and size of the organization in which the innovation project took place and the environment in which the innovation was developed.

Firstly, Luecke and Katz (2003) and Albury (2005) put a particular accent on the first dimension, innovation type, distinguishing product, process and service innovations. Secondly, Jacobs and Snijders (2008) considered the degree of novelty presenting the fuzzy approach of innovation. Albury and Mulgan (2003) spoke about incremental, radical and systemic innovation. Also, thirdly, Hartley (2006) showed the distinction between innovations that took place in a private firm or in a public organization. Moreover, fourthly, the size of organization should be taken into account as well. In the end, as a fifth dimension, the stability of the environment relies on the relationship with the management style.

\section{Knowledge and Knowledge Management Perspectives for a Society in Continuous Development}

Knowledge management is one of the most debated subjects today. The main questions 
that we have decided to focus in this part of our study and to which we have tried to give an answer are: what does the activity or the process of knowledge management refer to? And why did knowledge management become in such short term so important and so vital for all of us?

\section{Knowledge and Knowledge Management, a Theoretical Approach}

In terms of conceptual determination, knowledge is the very next step that comes after data and information, and the one that generates wisdom if properly used. Knowledge is far more than data and information. Les Alberthal (1995) stated the following ideas in terms of the relationship that exists between data, information, knowledge and wisdom: "Like water, this rising tide of data can be viewed as an abundant, vital and necessary resource. With enough preparation, we should be able to tap into that reservoir - and ride the wave
- by utilizing new ways to channel raw data into meaningful information. That information, in turn, can then become the knowledge that leads to wisdom."

\section{Knowledge and Knowledge Management, as Drivers of Nowadays Society}

Knowledge and knowledge management, together with innovation and innovation skills, are one of the main drivers of our society. In this matter, Neil Fleming stated the following ideas in his studies: a collection of data is not information; a collection of information is not knowledge; a collection of knowledge is not wisdom; a collection of wisdom is not truth.

The graphic bellow presents the steps necessary to generate knowledge and furthermore wisdom (see, in this matter, Graphic no. 1: "Knowledge and knowledge management, as drivers of nowadays society").

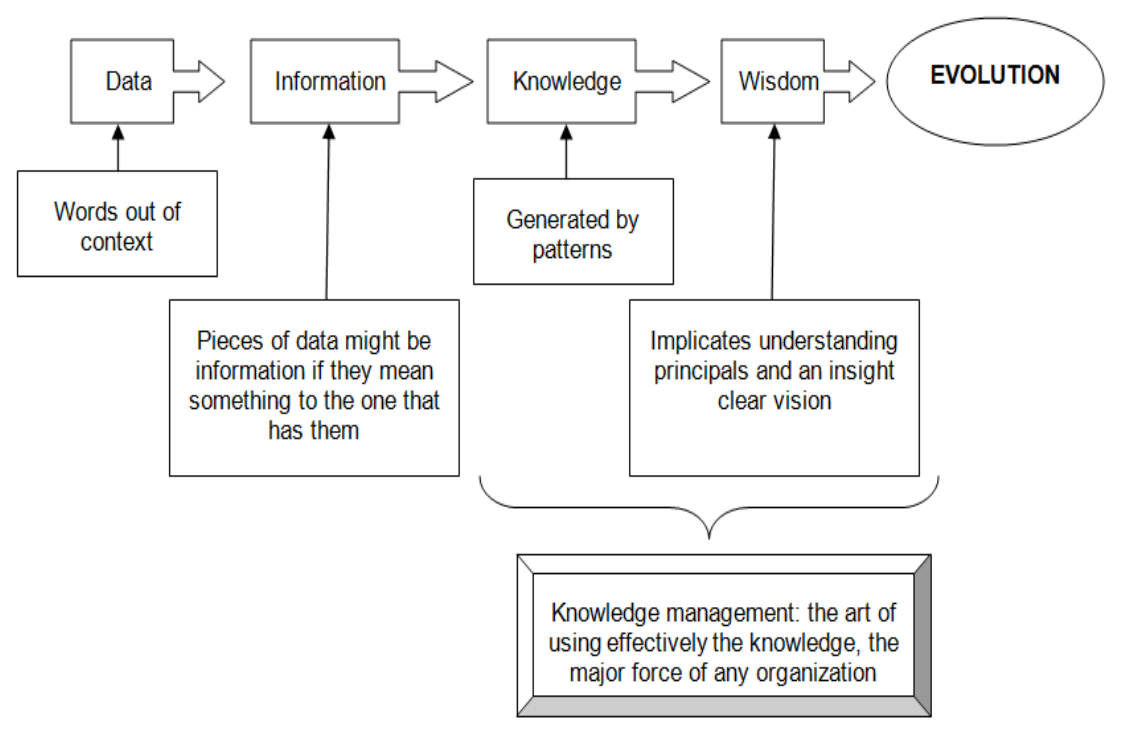

Fig. 1: “Knowledge and Knowledge Management, as Drivers of Nowadays Society” Source: the Authors

The steps represented above state the importance of knowledge and knowledge management and present the idea that knowledge and wisdom properly combined, are able to create evolution and are the main triggers of a learning organization.
Learning Organizations Perspectives for a Society in Continuous Development

The learning organizations are those organizations which are extremely innovative and center their activity on 
knowledge generation, appropriation and exploitation. The main statement is that organizations which are mainly focused on investing in new technology and machinery to make the production more efficient loose the main asset possible: knowledge. A real and potent organization interested in being in the top in terms of business knows that investing in the flow of know-how is the key to success.

\section{Learning Organizations, a Theoretical Approach}

In terms of learning organizations we are presenting three definitions:

- The first definition referring to learning organizations states that learning organizations are organizations where people continually expand their capacity to create the results they truly desire, where new and expansive patterns of thinking are nurtured, where collective aspiration is set free, and where people are continually learning to see the whole together. (Senge, 1990)

- The second definition referring to learning organizations shows that learning organizations or learning companies represent a vision of what might be possible. Moreover it is not brought about simply by training individuals, it can only happen as a result of learning at the whole organization level. The learning organization or company facilitates the learning of all its members and continuously transforms itself. (Pedler et. al., 1991, 1996)
- The third definition referring to learning organizations presents the fact that learning organizations are characterized by total employee involvement in a process of collaboratively conducted, collectively accountable change directed towards shared values or principles. (Watkins and Marsick, 1992)

\section{Learning Organizations, as Drivers of Nowadays Society}

In our opinion, as research economists, learning organizations are those organizations which prove to be able to provide continuous learning opportunities; capable to use learning to reach their goals; risk-taking; powerful enough in order to link individual performance with organizational performance; encouraging in order to make people to share openly their ideas; characterized by creativity, energy, effectiveness.

Learning organizations are based on a very competitive system and are extremely dynamic. They always put base on the future, and think on long term opportunities. Senge (1990) has stated in this matter that: "The systems viewpoint is generally oriented toward the long-term view. That's why delays and feedback loops are so important. In the short term, you can often ignore them; they're inconsequential. They only come back to haunt you in the long term".

The main characteristics of learning organizations have been synthetized in the picture bellow (see, in this matter, Graphic no. 2: "Learning organizations, as drivers of nowadays society"). 


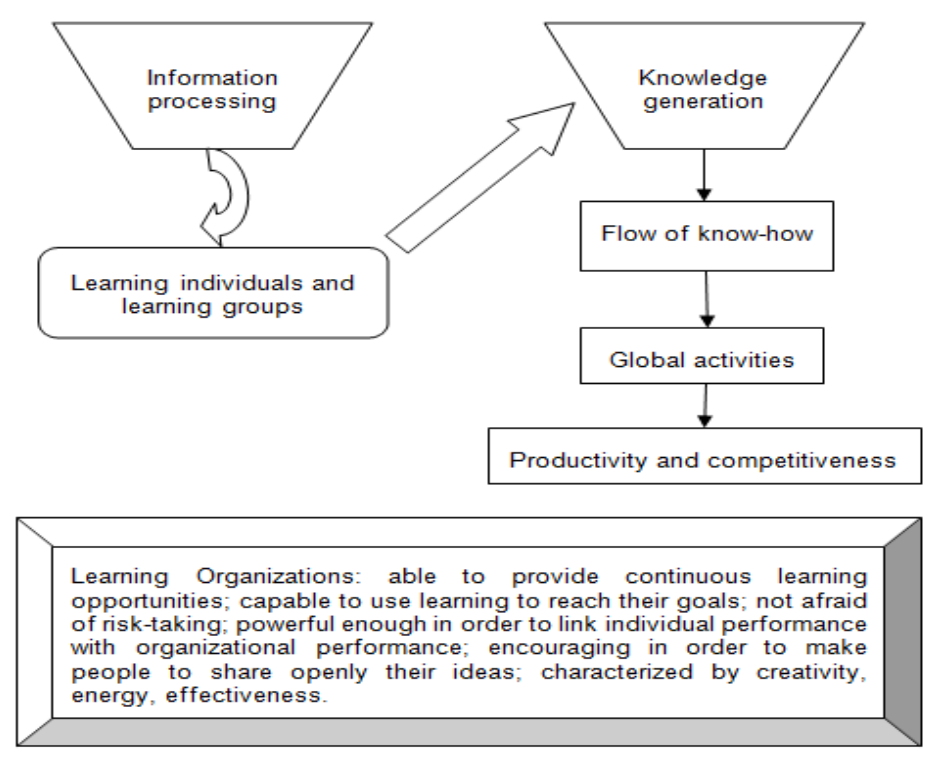

Fig. 2: "Learning Organizations, as Drivers of Nowadays Society" Source: the Authors

\section{The Case of Romania in Terms of Learning Organizations}

Romania is a country where one can find great potential in terms of knowledge, but unfortunately its use is not at its real capacity. Our research paper focuses on the place and the role of knowledge management in Romania. Our research method focused on 200 subjects (adult individuals) from 5 organizations in Romania, and was done on a period length of three years, respectively between 2009 and 2011.

Our analysis focused on the way in which organizations in Romania see knowledge and embrace the idea that knowledge is the main asset in any society.

The main aspect that we focused on was the role of personal and professional development, due to the fact that we strongly believe that change has first to come from us and then properly implemented in an organization. The questioner that we have made and that referred to the personal and professional development of individuals, and the analysis made afterwards generated specific results (see, in this matter, Graphic no. 3: "Case study on Romanians personal and professional development at the organizational level'): around $60 \%$ of the total individuals from the organizations that we have interviewed believe that a main trigger of an organization stands into its potential to generate knowledge; around $40 \%$ of the total individuals from the organizations that we have interviewed believe that the organization should send its employees to more trainings according to their position and the activity they are involved in; more than $80 \%$ of the individuals that have stated that more trainings should be done at the organizational level believe that the trainings should be fully paid by the company, $15 \%$ are willing to contribute in some manner to the costs and $5 \%$ have admitted that they went by themselves at some training seminars in order to perfect themselves or improve their effectiveness.

As a particularity, our study has shown us that individuals are able to realize the role of knowledge, but more than often they associate it with new technology and furthermore with its implementation which results into change decisions that are in the end regarded as a very delicate subject, which we have presented at the beginning of our study, respectively the possibility of losing their jobs. 


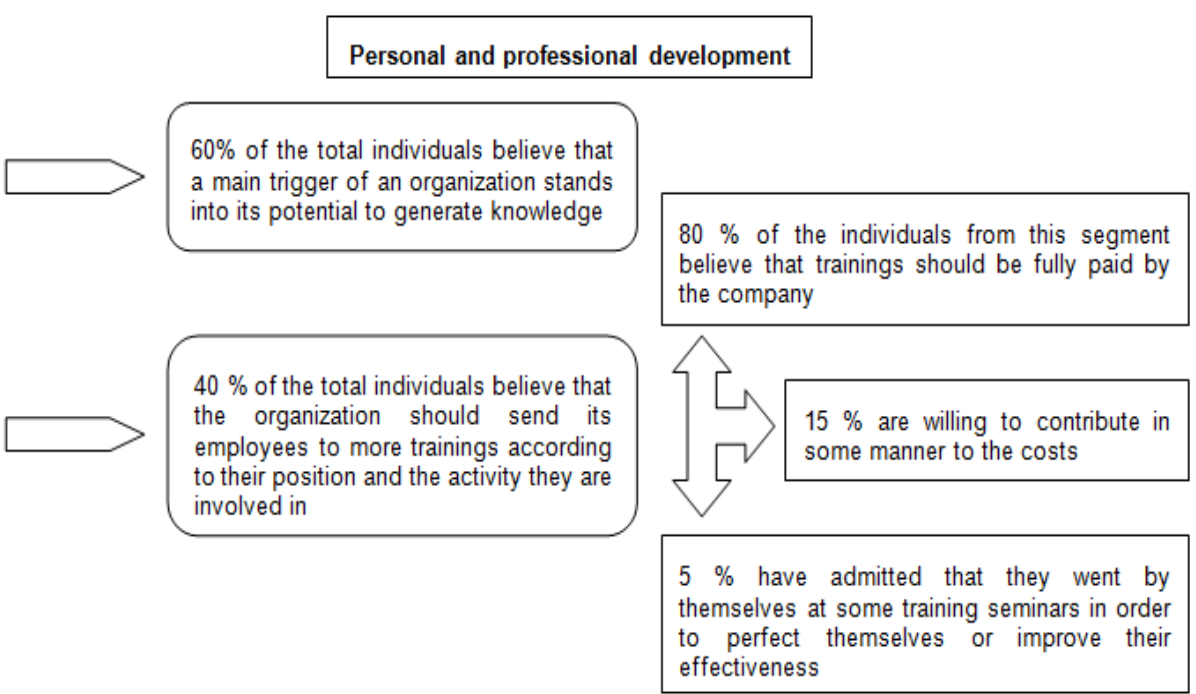

Fig. 3: "Case Study on Romanians Personal and Professional Development at the Organizational Level" Source: the Authors

In conclusion, as an interesting phenomenon, in terms of individuals' perception on knowledge and knowledge management at learning organizations level, we have seen that, at a first glance, individuals show a great availability and a high openness rate in terms of embracing, for example, new innovative methods and new technologies, but, in reality, the organizations confront themselves with far more problems than the ones of implementing or not new technologies, of using correct or not knowledge and so on. Far more important, in terms of obstacles that learning organizations have to face, are the ones regarding the motivations of their employees. According to the results generated by our study and the use of our research methodology, an unsatisfied employee in any type of organization, in terms of money and bonuses motivation and/or the opportunity to promote at the organizational level and/or a conductive organizational environment, may be extremely reluctant to anything that relates to future learning processes or tasks or working openness in terms of knowledge innovation.

\section{Conclusions and limitations}

The potential of each individual and of each company lies in its capacity to value knowledge and to manage it accordingly. In most cases, several individuals, and several organizations have the chance to have access to the same knowledge, but the advantage relates into the know-how competences that someone either has or not. That is probably the reason why knowledge management is far more than a process or a specific activity, it a pure form of "art".

In terms of Romania's potential in terms of developing competitive learning organizations, our analysis has shown that around $60 \%$ of the total individuals interviewed believe that a main trigger of an organization stands into its potential to generate knowledge; around $40 \%$ of the total individuals interviewed believe that the organization should send its employees to more trainings according to their position and the activity they are involved in, and out of this category more than $80 \%$ of the individuals believe that the trainings should be fully paid by the company, $15 \%$ are willing to contribute in some manner to the costs and $5 \%$ have admitted that they went by themselves at some training seminars in order to perfect themselves or improve their effectiveness.

For future research we would like to see that in time more academics and 
researchers realize the importance of learning organizations in Romania and will start debating much more this theme. Of course, there is clear evidence that learning organizations have been a research subject for a couple of years but there is still much to be done at this level.

\section{References}

A CRIC Report for the Department of Trade and Industry (September, 2005). done by Bruce Tether, Andrea Mina, Davide Consoli and Dimitri Gagliardi, A Literature Review on Skills and Innovation. How Does Successful Innovation Impact on the Demand for Skills and How Do Skills Drive Innovation?, ESRC Centre for Research on Innovation and Competition University of Manchester, Manchester, M13 9QH, UK, site: http://www.cric.ac.uk/cric/staff/Davide_Co nsoli/dti.pdf

Alberthal, L. (1995). 'Remarks to the Financial Executives Institute,' October 23, Dallas, TX.

Albury, D. (2005). "Fostering Innovation in Public Services," Public Money \& Management, 25 (1), pp. 51-56.

Allenby, B. R. (1999). "Industrial Ecology: Policy Framework and Implementation," Englewood Cliffs, New Jersey, Prentice-Hall, Inc.

Bell, D. (1978). The Cultural Contradiction of Capitalism, Heinemann, London.

Drucker, P. F. (1985). Innovation and Entrepreneurship, UK: Pan Business Management.

Druckes, P. F. (1964). "Knowledge Worker: New Target for Management," Christian Science Monitor. Retrieved from http://drucker.cgu.edu.

Edvineson, L. \& Malone, M. S. (1997). Intellectual Capital: Realizing Your Company's True Value By Finding its Hidden Brain Power, New York, Harper Collins.
Fleming, N. D. "Coping with a Revolution: Will the Internet Change Learning?," Lincoln University, Canterbury, New Zealand, Retrieved on January.2012 from the Internet Site: http://www.varklearn.com/documents/information_and_kn owle.pdf

Freeman, C. (1982). The Economics of Industrial Innovation, 2nd edn, Frances Pinter, London Revolution, Oxford University Press.

Hayek, F. (1945). The Uses of Knowledge in Society, American Economic Review, 35, Pp. 1-18.

Keplan, R. S. \& Nortan, D. P. (1996). The Balanced Scorecard: Translating Strategy into Action, Boston: Harvard Business School Press.

Kirkland, L.- H. \& Thompson. D. (1999). "Challenges in Designing, Implementing, and Operating an Environmental Management System," Business Strategy and the Environment, 8, Pp. 128-143.

Klein, K. J. \& Speer Sorra, J. (1996). "The Challenge of Innovation Implementation," Academy of Management Review 21(4), Pp. 1055-1080.

Leonard-Barton, D. (1995). Wellsprings of Knowledge - Building and Sustaining Sources of Innovation, Boston: Harvard Business School Press.

Nonaka, I. \& Takuchi, H. (1995). The Knowledge - Creating Company: How Japanese Companies Create the Dynamics of Innovation, New York; Oxford University Press.

Pedler, M., Burgoyne, J. \& Boydell, T. (1991, 1996). The Learning Company. A Strategy for Sustainable Development, London: Mcgraw-Hill.

Senge, P. M. (1990). 'The Fifth Discipline: The Art and Practice of the Learning Organization,' New York: Doubleday. 
Senge, P. M. \& Kleiner, A., Roberts, C., Ross, R., Roth, G., Smith\|, B. \& Guman, E. C. (1999). "The Dance of Change: The Challenges to Sustaining Momentum in Learning Organizations,"

Senge, P. M., Kleiner, A., Roberts, C., Ross, R., Smith, B. J. (1994). The Fifth Discipline FieldBook: Strategies and Tools for Building a Learning Organization, New York, Doubleday.

Sveiby, K. (1996). 'What Is Knowledge Management?,' Retrieved June 6, 2010 from http://www.sveib.com.

Sveiby, K. E. (1997). The New Organizational Wealth: Managing and Measuring Knowledge-Based Assets, Berrett Koehler, San Francisco, CA.

Watkins, K. E. \& Marsick, V. J. (1992). "Building the Learning Organization: A New Role for Human Resource Developers," Studies in Continuing Education 14(2): 11529.

Webster's New Collegiate Dictionary on Line, http://www.merriam-webster.com/

Whitley, R. (2000). "The Institutional Structuring of Innovation Strategies: Business Systems, Firms Types, and Patterns of Technical Change in Different Market Economies," Organizations studies 21 (5), pp. 855-887. 